\title{
Sports Facility Safety Plans: A Framework for Evaluation of Evacuation Times
}

\author{
Massimo de Falco, Donato Di Stasi, Carmine Novellino \\ Department of Industrial Engineering, University of Salerno, Salerno, Italy
}

Email address:

ddistasi@unisa.it (D. Di Stasi)

\section{To cite this article:}

Massimo de Falco, Donato Di Stasi, Carmine Novellino. Sports Facility Safety Plans: A Framework for Evaluation of Evacuation Times. American Journal of Sports Science. Vol. 4, No. 4, 2016, pp. 69-76. doi: 10.11648/j.ajss.20160404.12

Received: May 22, 2016; Accepted: May 31, 2016; Published: June 18, 2016

\begin{abstract}
The objective of the work is to propose a model that can analyse the conformity of a stadium, sports field or other sports facility to Italian safety norms. The model serves in particular to analyse the adequacy of the facility 'safety plan' in terms of its definition of the stages, procedures and times for evacuation of the facility. The model is structured in modular form, beginning with an analysis of the conformity of the sports facility to the applicable norms. This first stage applies a series of purpose-developed checklists to describe the facility as defined by Ministerial Decrees 18/03/1996 and 06/06/2005. Following this, the facility is characterized in terms of its location, dimensions and structural type. The next stages are: i) the analysis and estimation of the evacuation times, on the basis of the information previously gathered on the facilities; ii) the evaluation of conformity with the safety plan for the particular facility, applying the results from the previous steps. The proposed framework can be used as an instrument in support of decision-making for improvement in the safety levels of the sports facility, through augmenting the effectiveness of procedures and equipment, while also considering the economic implications of the potential improvements.
\end{abstract}

Keywords: Safety, Framework, Sports Facilities, Evacuation, Italian Safety Norms

\section{Introduction}

The objective of the research is to propose a model that can analyse the conformity of a stadium, sports field or other sports facility to Italian safety norms. The model serves in particular to analyse the adequacy of the facility 'safety plan' in terms of its definition of the stages, procedures and times for evacuation of the facility. The model is structured in modular form, beginning with an analysis of the conformity of the sports facility to the applicable norms. The proposed framework can be used as an instrument in support of decision-making for improvement in the safety levels of the sports facility, through augmenting the effectiveness of procedures and equipment, while also considering the economic implications of the potential improvements.

The paper propose a framework (Figure 1) for the analysis and evaluation of the conformity of sports stadiums and sports fields to regulations on safety, as defined under Italian law ${ }^{1}$, focusing in particular on the aspect of evacuation of the facilities. The method applies simulation software for the estimating the evacuation times necessary, and is developed as a framework consisting of a series of steps:

1) Analysis of the stadium's physical conformity to Italian norms D.M. 1996-2005;

2) Identification of the stadium's significant features;

3) Analysis and estimate of evacuation times;

4) Evaluation of conformity to the facility 'safety plan', prepared as required under D.M. 1996-2005.

5) The model provides the stadium owner or the user teams with options for targeted interventions to increase the structure's safety and the effectiveness of the related equipment, including economic estimates of the modifications.

1 Ministerial decree of 18 March 1996, Safety norms for the construction and operation of sports facilities, amended and supplemented by Ministerial decree of 6 June 2005 decree 06/06/2005 (hereafter abbreviated as D.M. 1996-2005). 


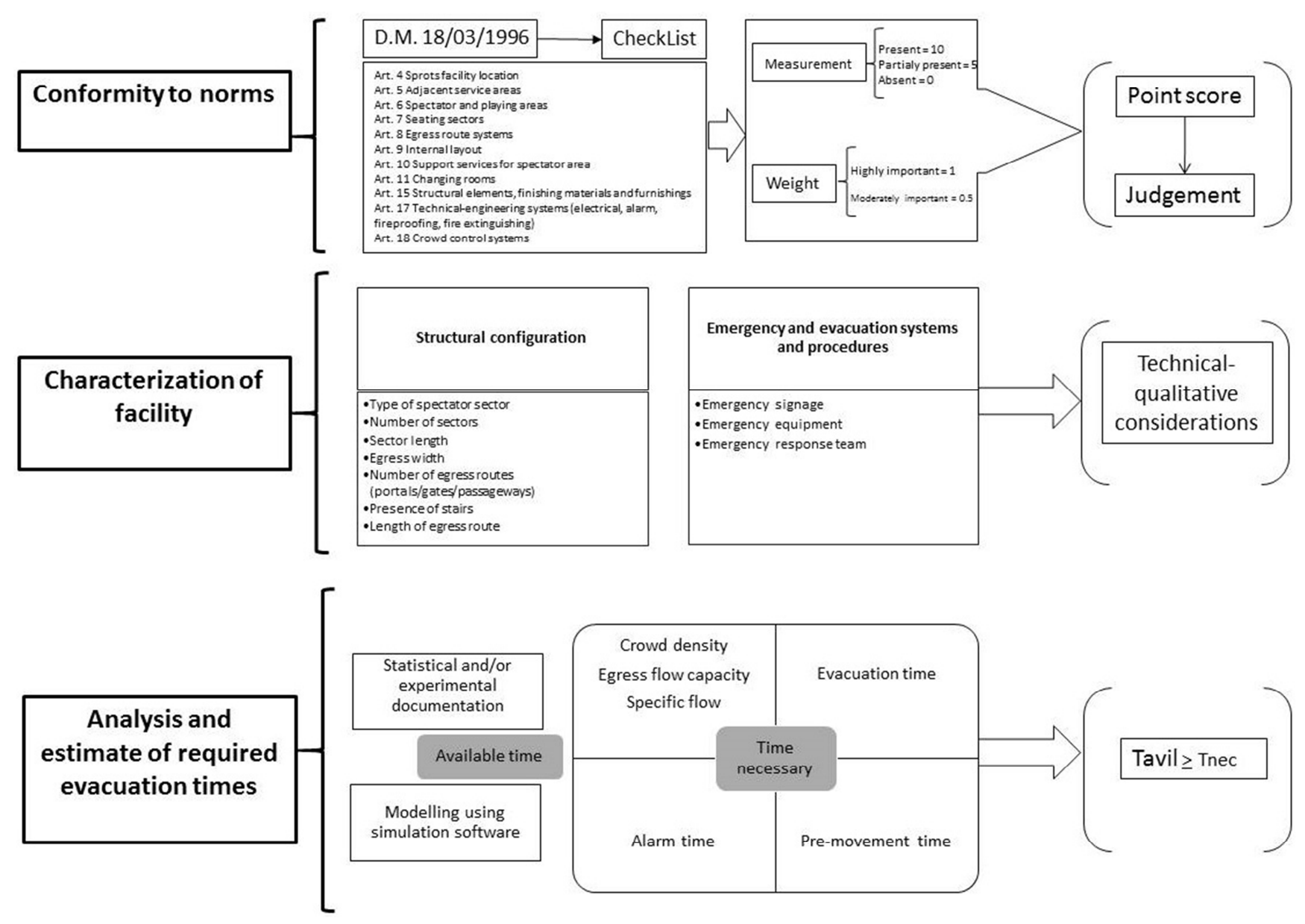

Figure 1. Framework.

\section{Analysis of the Facility's Conformity to Norms}

Step 1 of the framework uses a series of checklists detailing the normative requirements for sports facilities under D.M. 1996 and 2005.

The checklists break down the regulatory requirements into their main articles and aspects, as follows:

Article 4. Sports

facility location

Article 5. Adjacent service areas

Article 6. Spectator and playing areas

Article 17. Technicalengineering systems (electrical, alarm, fireproofing and fire extinguishing)
Article 7. Article 10. Support Seating services for spectator sectors area

Article 8.

Egress route Article 11. Changing systems

Article 9. Internal layout

Article 18. Article 6. Separation Crowd systems between control spectator and player systems areas
The level of adequacy is evaluated by means of KepnerTregoe (K-T) decisional analysis. K-T analysis is a quantitative comparison method in which a team of experts provides a numeric ordering of evaluation 'criteria' and higher level 'alternatives', based on the judgement of each individual expert. Every evaluation criterion is assigned a relative value with respect to the other criteria, from 1 (less important) to 10 (more important), with this score establishing the criterion 'weight'. The alternatives and/or parameters are also individually ordered with a score, after being related to the weights. The total score for each alternative is then determined, through multiplying its score by the weight of each criterion, then summing the values obtained. For a given decisional problem, the best alternative is that with the greatest total. In our case, the scores express an overall score concerning the sports facility's conformity to the set of parameters considered in the quantitative evaluation. The proposed method is easily implemented. The results reveal the critical issues in the management of the sports facility through the weights and scores assigned to the set of parameters taken into consideration.

The expert team carries out an evaluation of conformity for each normative Article, using a 'grid' checklist that leads 
to calculation of the total score for that article (Table 1). The team judges the conformity of the facilities to the Article, noting the judgements as point-score measurements on the grid. There are three possible measurements concerning the conformity of the facility features to the normative clauses: Present $=10$; Partially present $=5$; Absent $=0$.

The 'safety item' indicated by each article is assigned a weight that takes account of its relevance to the facility's safety plan: Highly important -1 ; Moderately important $=0.5$.

The completion of this process for all the individual normative clauses results in a total point score for the Article, which is converted into a judgement according to the four percentage classes at the bottom of the table.

Table 1. Checklist and calculation grid for conformity to a regulatory article.

\begin{tabular}{|c|c|c|c|c|c|}
\hline Checklist for Article number: & \multicolumn{5}{|l|}{ Date: } \\
\hline $\begin{array}{l}\text { Judgement of conformity to Article safety item } \\
\text { (based on \% of maximum score): }\end{array}$ & \multicolumn{5}{|c|}{ Judgement } \\
\hline Insufficient $\leq 30 \%$ & \multicolumn{3}{|c|}{ Measurement } & \multicolumn{2}{|l|}{ Weight } \\
\hline $30 \%<$ Poor $\leq 50 \%$ & 10 & 5 & 0 & 1 & 0,5 \\
\hline $\begin{array}{l}50 \%<\text { Fair } \leq 70 \% \\
\text { Good }>70 \%\end{array}$ & Present & Partially present & Absent & Highly important & Moderately important \\
\hline $\begin{array}{l}\text { Clause 1: } \\
\text { Clause 2: } \\
\text { Clause 3: }\end{array}$ & & & & & \\
\hline etc. & & & & & \\
\hline 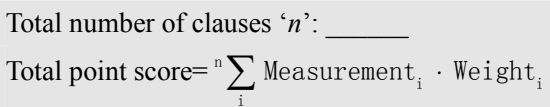 & & & & & \\
\hline
\end{tabular}

The process is repeated for every article of the two Ministerial decrees governing stadiums and sports fields (D.M. 1996-2005), and the individual results are transposed to the following summary table.

Table 2. Summary table of overall conformity to D.M. 1996-2005.

\begin{tabular}{lll}
\hline Checklist & Score & Judgement \\
\hline Article 1 & & \\
Article 2 & & \\
etc. & \\
\hline
\end{tabular}

The summary table provides a global evaluation of the stadium or sports field, indicating the conformity of the facility to the two norms, in terms of the total points for each
Article. Given the results of the summary table, the facility owner or the teams operating there can consider the interventions that would improve the levels of safety, including the economic estimates of to what extent the interventions would determine benefits of greater safety.

\section{Identifying the Stadium Characteristics}

This step characterizes the sports facility in terms of its functional and formal type, location, surface areas, and structural configuration. Table 3 presents three of the parameters considered.

Table 3. Parameters identifying the sports facility character.

\begin{tabular}{|c|c|c|}
\hline Sector capacity C & $C=\frac{L}{0,48}[$ pers $](1)$ & $\begin{array}{l}L \text { is the linear measure of the sector seating tiers, in metres; } 0.48 \text { is the chest } \\
\text { width of an average person }\end{array}$ \\
\hline Facility maximum capacity $C_{\max }$ & $\mathrm{C}_{\max }=\mathrm{C}$ Set (2) & $C$ is the sector capacity; Set is the number of sectors in the facility \\
\hline $\begin{array}{l}\text { Crowd density } \rho \text { (regulated for spectator } \\
\text { facilities by D.M. } 10 / 03 / 1998 \text { ) }\end{array}$ & $\mathrm{P}_{\text {spectator }}=3.5\left[\frac{\text { pers }}{m^{2}}\right](3)$ & $\begin{array}{l}\text { This value is reduced to } 2\left(\frac{\text { pers }}{m^{2}}\right) \text { in cases where the facility is used for 'special } \\
\text { events' (e.g. music concerts). }\end{array}$ \\
\hline
\end{tabular}

The analysis continues with an examination of the more detailed structural configuration:
Type of spectator sector
Number of sectors
Number of egress routes (portals/gates/passageways)
Sector length
Presence of stairs
Egress width
Length of egress route

The presence, sensitivity and reliability of systems for detection and response to emergencies are also analysed and checked, and characterized as either positive or negative:
Emergency signage
Emergency equipment
Emergency response team

All of this information serves towards the model's core module for measuring the evacuation times, as seen in the next section. 


\section{Analysis and Estimate of Necessary Evacuation Times}

In this stage, the stadium structural information now serves in calculating and/or estimating the times necessary for evacuation. The parameters used in the calculation are:

Crowd density $\rho$-the maximum number of persons permitted per gross unit of surface area (persons/ $\mathrm{m}^{2}$ ). Calculation of the size of the egress-ways is based on the maximum possible number of persons present in the whole of the spaces of a particular area, relative to the gross surface area of the area.

Egress flow capacity $\varphi$-the number of persons that can move in safe conditions through an egress of $60 \mathrm{~cm}$ width. Sixty $\mathrm{cm}$ is an apportionment based on the average form of a person in 'plan view', resembling an ellipse with axes of 60 $\mathrm{cm}$ and $45 \mathrm{~cm}$.

Specific flow $\mathrm{F}_{\mathrm{s}}$-the number of persons that pass through a point of the egress route per unit of time and effective width.

Alarm time $\mathrm{T}_{\mathrm{ala}}$-the time elapsed between the beginning of a situation of concern and the moment when it is detected and signalled. The time can decrease if detection systems are installed in the area. The parameter describes the necessary interval from the beginning of a situation of elevated danger to its signalling to the public and full safety team.

Pre-movement time, or evacuation start time $T_{\text {pre }}$-the time interval between the situation detection and signalling and the beginning of the evacuation process. The time is affected by: the presence of appropriate exit signage (which must be sufficient but not excessive); the safety team preparation; the characteristics of the people present (e.g. knowledge of the facilities, psychological and physical condition, awareness of pre-planned procedures).

Travel time $T_{\text {trav }}$-the time required for a person to move from their initial location to the first identifiable safe place.

Evacuation time $T_{\text {eva }}$-the time required for a person to complete evacuation from the facility or reach a safe place. This is affected by: the number, physical condition and age of the persons present; their knowledge of the facilities; the number and effective width of the egress ways and safety exits; the effective length of the egress routes; crowd density.

The estimation of evacuation time assumes that the persons' speed of egress (velocity) in the different segments of the exit route is constant. The parameter is determined by experimental observation and documented experience of the movement of persons in case of emergencies.

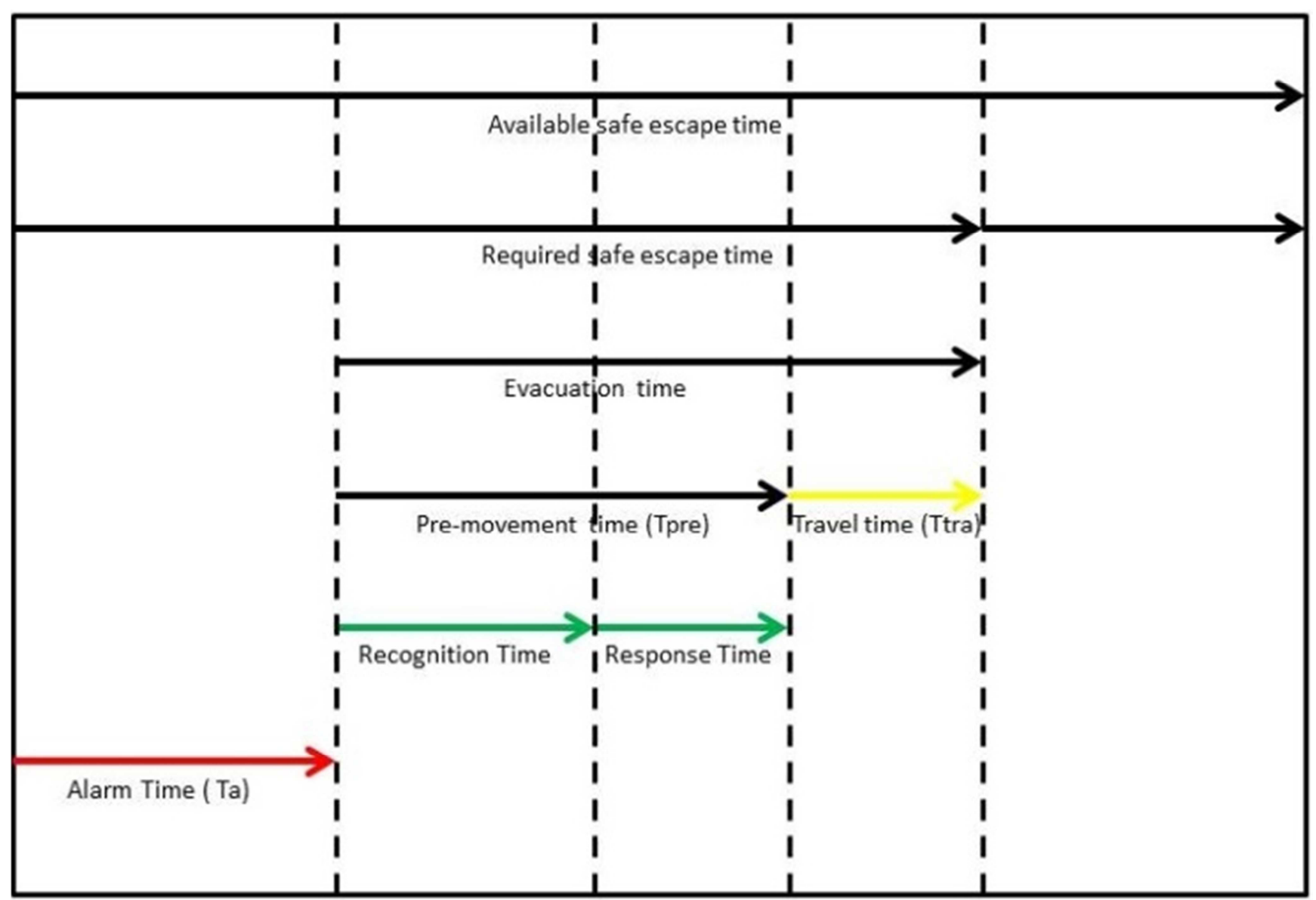

Figure 2. Estimation of available and required evacuation times. 
As seen in Figure 2, the objective for the model is to ensure that the time necessary for evacuation is less than the available time.

$$
\begin{gathered}
\text { TAVAIL } \geq \text { TNEC } \\
(\text { TALA }+ \text { TPRE }+ \text { TEVA }) \geq \text { TNEC }
\end{gathered}
$$

The model provides a margin of safety sufficient to account for the uncertainties in the hypotheses concerning calculation of the component parameters, as well as the potential variations in conditions of the danger and evacuation events. The safety margin is set at $40 \%$ of the total evacuation time.

The alarm time is divided into the time for detection and for launching the general alarm. Both of these depend on the presence or absence of detection and alarm systems and their operational condition. The total alarm time is assumed as between 1 and 1.5 minutes. The effective alarm time must be calculated, to evaluate if it falls within the necessary time previously indicated.

The pre-movement time depends on the organization of emergency procedures, the preparedness and action of the emergency team, and in particular on the exit signage. Exit signage alone has a $\pm 20 \%$ effect on the total evacuation time. Here again, the effective pre-movement time must be calculated by in-situ observation, to observe whether this falls within what is indicated as necessary.

The initial factor in the measurement of evacuation time is the calculation of the actual crowd densities for the sports facility under analysis, expressed for each sector as the ratio of total persons to surface area:

$$
\rho=\frac{C}{S}\left[\frac{\text { pers }}{m^{2}}\right]
$$

The next step is the estimate of the velocity of egress of the persons along the components of the egress route, which as noted above is assumed as constant. This parameter depends on a velocity factor $k$, which varies according to the characteristics of the route that the persons must follow, as well as the constant factor $a=0.266\left(\frac{\mathrm{m}^{2}}{\text { pers }}\right)$. Thus, in formula, velocity of egress

$$
v=k-a \cdot k \cdot \rho
$$

measured in $\left[\frac{m}{s}\right]$, where $k$ can assume the following values:

Table 4. Factor $k$ in speed of egress, in function of different structural components.

\begin{tabular}{lll}
\hline Egress component & & $\boldsymbol{k}$ \\
\hline Corridor, aisle, ramp, doorway & & 1.4 \\
Stair, riser $[\mathbf{c m}]$ & Stair, tread $[\mathbf{c m}]$ & \\
19 & 25.4 & 1 \\
17.2 & 27.9 & 1.08 \\
16.5 & 30.5 & 1.16 \\
16.5 & 33 & 1.23 \\
\hline
\end{tabular}

From the equation, we see that velocity of egress $v$ is inversely proportional to the density of persons that must transit via a certain passageway, as presented in Figure 3.

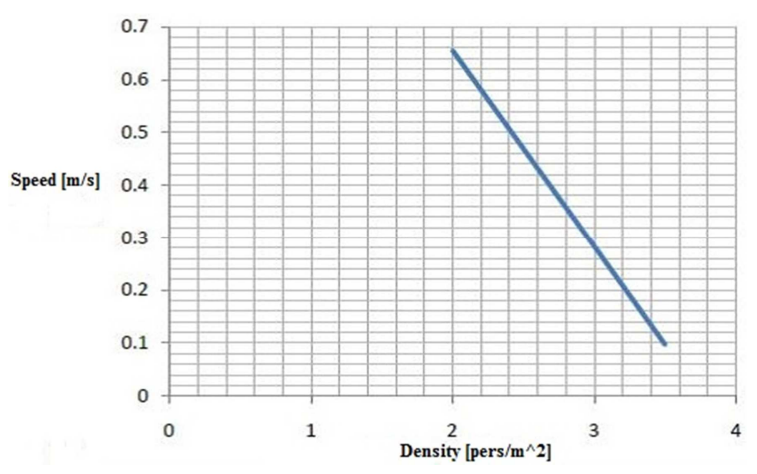

Figure 3. Relation of velocity of egress to density of persons.

To obtain homogenous data representing the crowd density and the width of the egress-ways, we use the 'specific flow':

$$
F_{s}=\rho v\left[\frac{\text { pers }}{m \cdot s}\right]
$$

The egress flow capacity $\varphi$ along an egress-way is related to the specific flow $F s$ and to the width of the egress route under examination:

$$
\varphi=F_{s} \mathrm{~W}\left[\frac{\text { pers }}{\mathrm{m} \cdot \mathrm{s}} \cdot \mathrm{m}\right]
$$

The evacuation time is calculated for each facility area, and is obtained from the relation of the number of persons exiting by a given egress route $N$, the specific flow $F s$ and the egress route width $W$ :

$$
\mathrm{T}_{\mathrm{evac}}=\frac{N}{F_{S} \cdot W \cdot 60}[\mathrm{~min}]
$$

The time necessary for the total evacuation of the sports facility is obtained by summing: i) the times necessary for the groups of people in the most disadvantaged positions to complete movement along the different route sections leading to a safe place; ii) the alarm time and iii) the premovement time, while iv) also taking account of the potential presence of individuals with physical limitations.

\section{Estimation of the Available Evacuation Times, by Simulation}

Implementation of the framework requires documentation or simulation of the available evacuation times for the sports facility under examination.

In this section we demonstrate the procedures for testing the adequacy of the safety plan, prepared in accordance with D.M. 1996-2005 for a specific sports field facility. We specify the parameters, particularly for the tiered seating sectors, in order to estimate the probable evacuation times under varying procedures, using different egress routes and under different parameters of flow, comparing the simulated evacuation times with the necessary times, calculated as above.

In the example of the sports field below (Figure 4), we divide the facility in three areas to facilitate the documentation and analysis. 


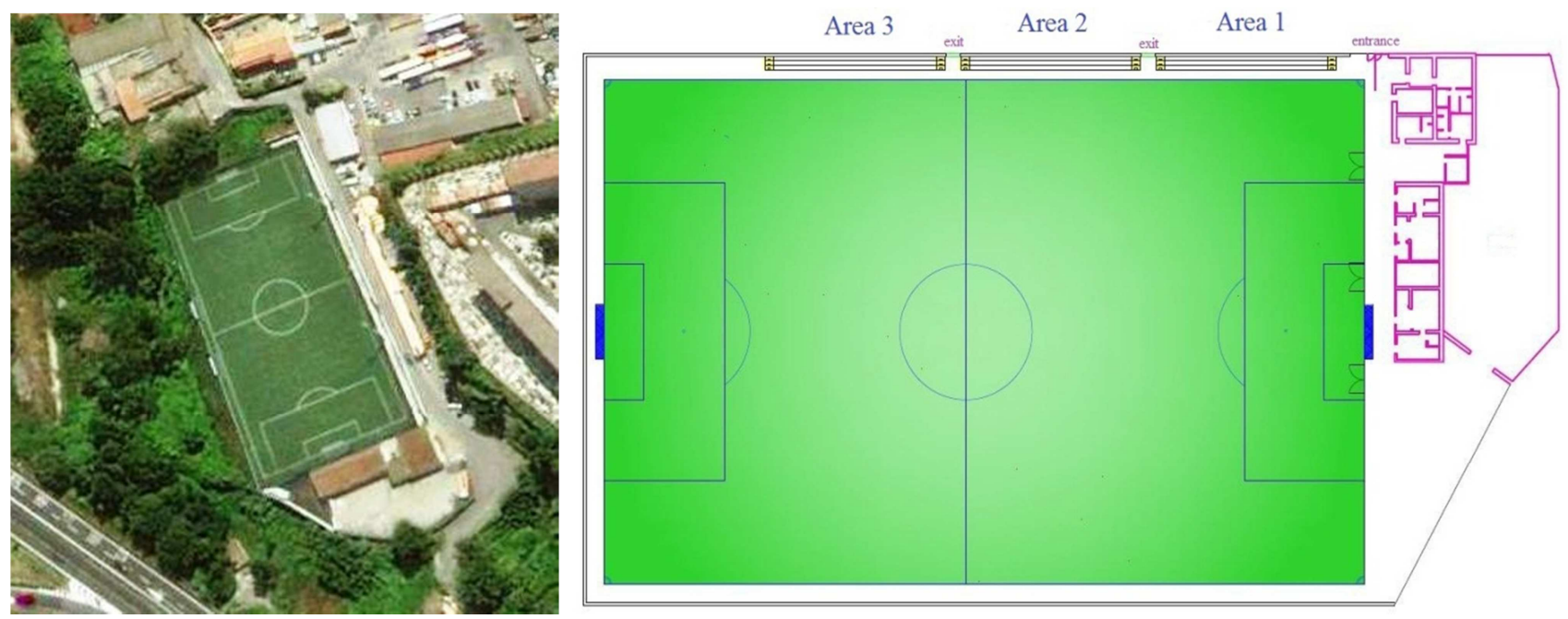

Figure 4. Plan views of a sports field with 3 tiered seating area.

Next we model the structure for each area, as seen in Figure 5 for the example of area 1.

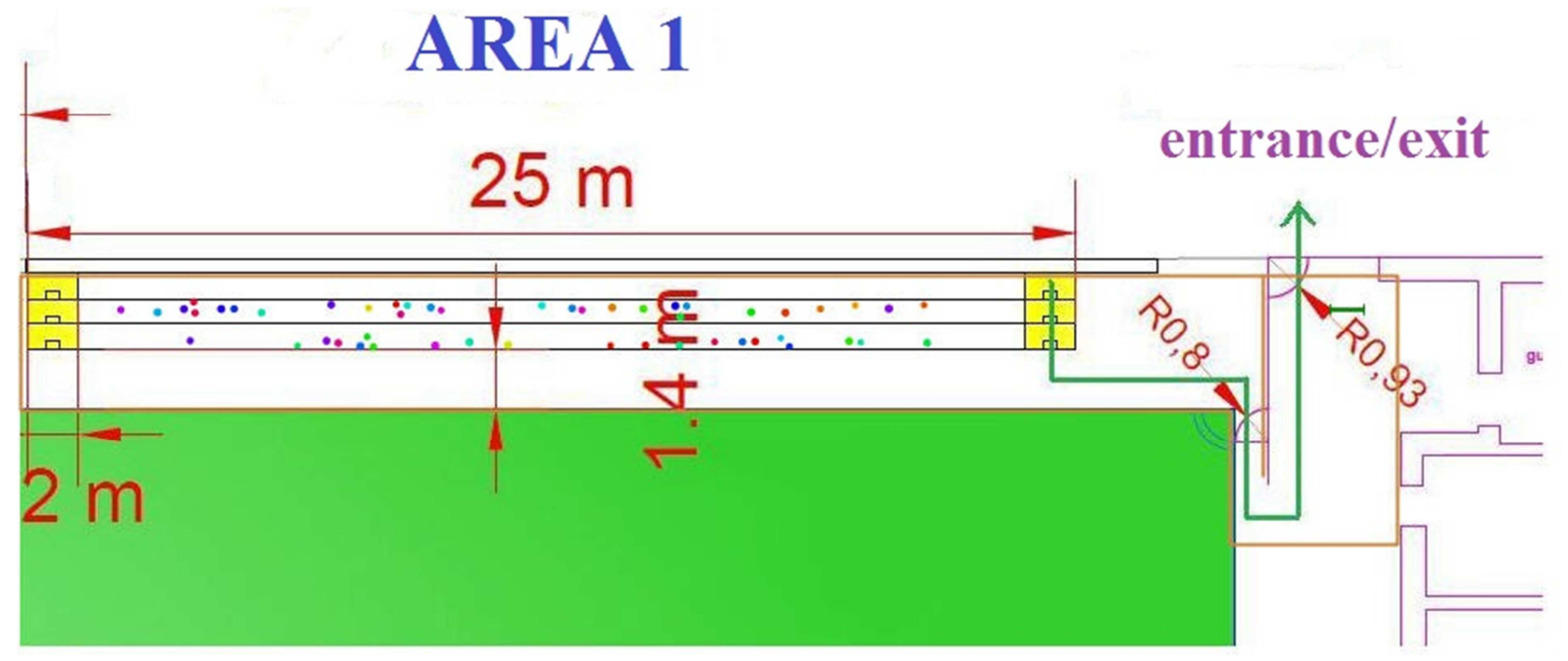

Figure 5. Modelling of a single area

Finally, as shown in Figure 6, we carry out repeated simulations of evacuation using readily available multi-method simulation software, ${ }^{2}$ under scenarios of different egress routes and different parameters of flow.
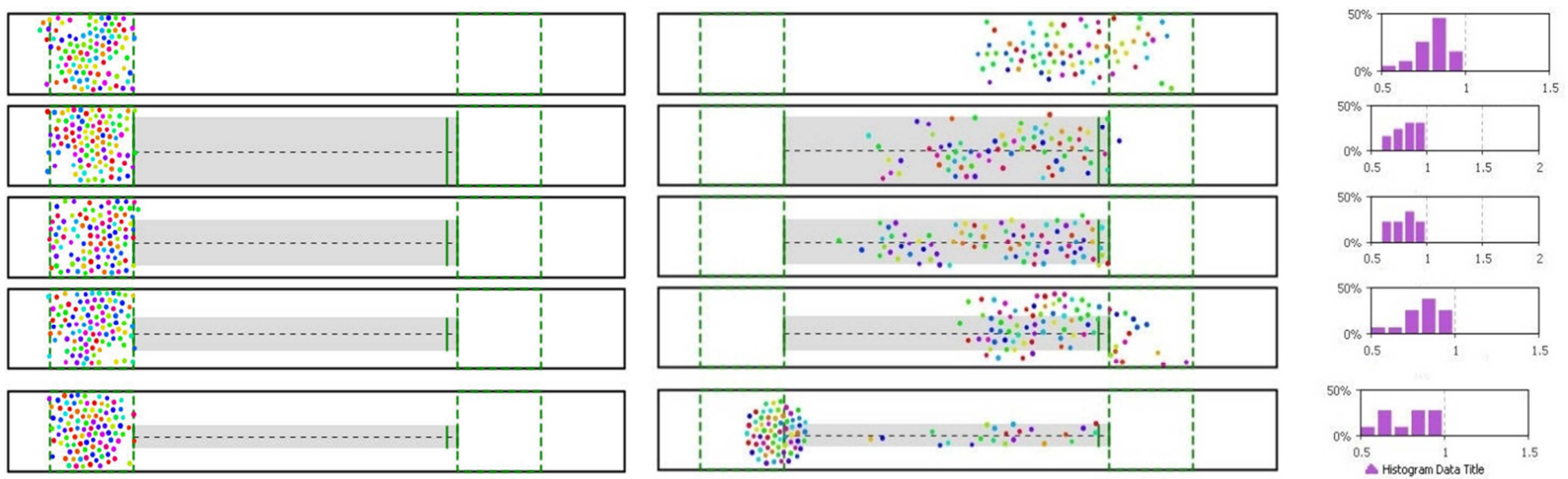

2 AnyLogic Multimethod Simulation Software, http://www.anylogic.com/, last consulted 31/01/2015. 

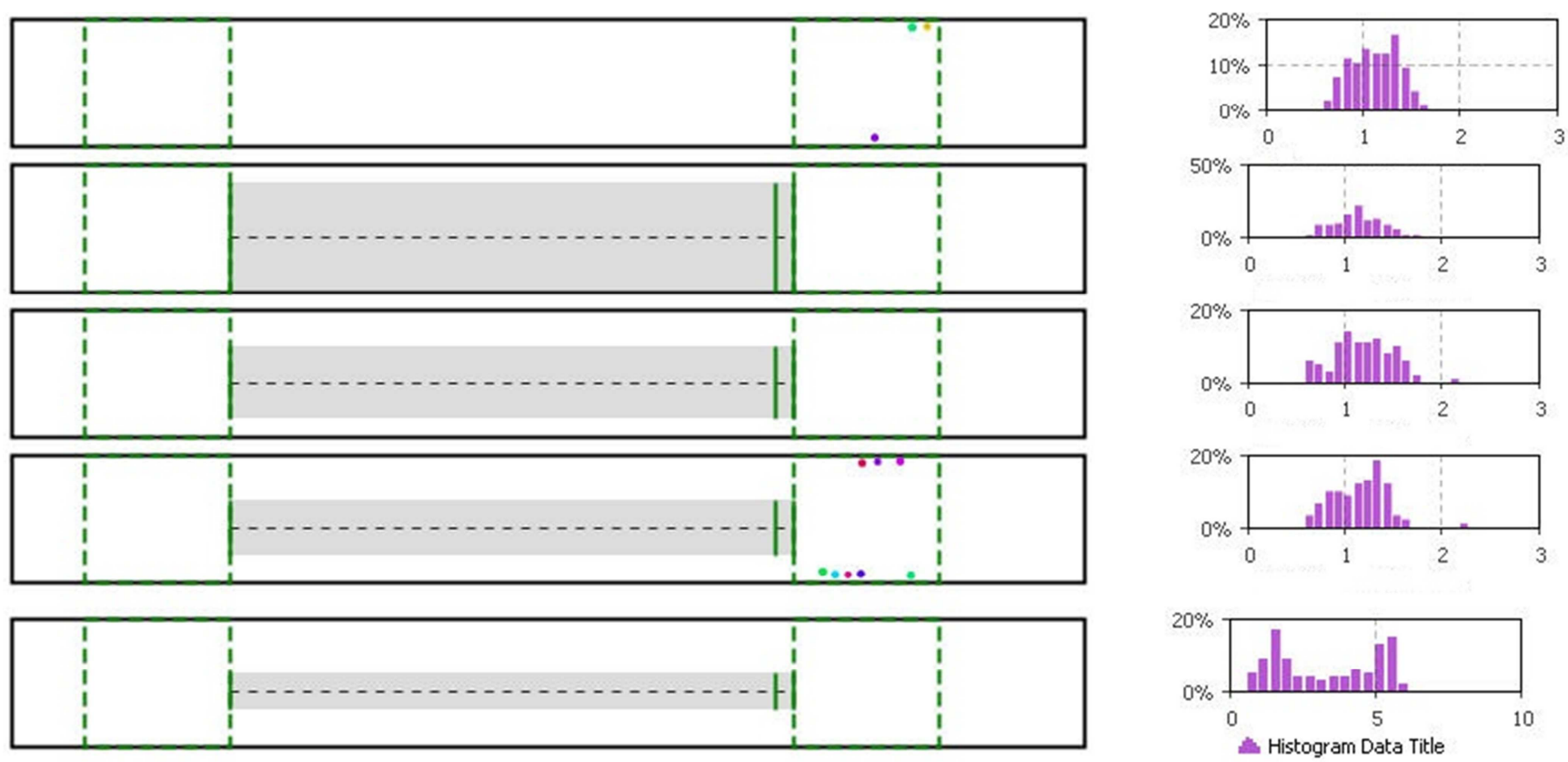

Figure 6. Simulation outputs.

\section{Evaluation of Conformity to Safety Plan}

The last stage consists of evaluating the conformity to the safety plan on the basis of the results obtained from the previous stages of data collection and analysis (Sections 4, 5).

Where the objective of the model is reached, meaning that the time necessary for evacuation does not exceed what is effectively available, then the safety plan is in conformity.

In the opposite case, where the necessary evacuation time exceeds what has been estimated for the evacuation of the facility, then the reasons for the excess time must be determined. The various time parameters must be reexamined and alternative solutions proposed and selected. For example in a situation where the alarm time is excessive, the facility owner would have to evaluate the condition and design of the detection and alarm systems, where these are present. Where such systems are lacking they would have to be installed, to reach improved performance levels. In cases where it is the pre-movement time that is excessive, the facility owner would have to examine the organization of the emergency team, as well as evaluate the sufficiency and placement of the emergency exit signage.

\section{Conclusions}

The proposed framework serves as an investigative instrument for a check of a sport facility's conformity to regulatory norms. It includes evaluation procedures that identify critical shortcomings in the sports facility, relevant to the individual articles of the current norms. The step of identifying the facility characteristics provides information necessary to the evaluation, for identifying parameters and subsequent application of the simulation software. The overall framework obtains useful information concerning evacuation times under varying parameters and evacuation procedures.

In future publications we intend to describe the framework in more detail, illustrating: i) the application of multi-method software in configuring alternative scenarios with differing escape routes and flows, and ii) the detailing of parameters and procedures for developing more efficient evacuation plans under both normal and critical conditions.

\section{References}

[1] Ministerial decree of 18 March 1996, Safety norms for the construction and operation of sports facilities, amended and supplemented by Ministerial decree of 6 June 2005 decree 06/06/2005.

[2] Italian National Olympic Committee norms for sports facilities.

[3] Ministerial decree of 10 March 1998, General criteria for fireprevention safety and the management of emergencies in workplaces.

[4] Musumarra L., La gestione della sicurezza negli impianti sportivi.

[5] Italian Football Federation system and security regulations.

[6] La Malfa A., Analisi delle c ondizioni di s icurezza delle $\mathrm{v}$ ie di e sodo s econdo l'approccio ingegneristico, in proceedings of Fire Safety Engineering: un nuovo approccio alla prevenzione incendi, INFORMA, Rome, 29 November 2001.

[7] Bianchi R., Progetto \& prodotto, in Impianti Sportivi.

[8] Lucantoni A., La gestione delle manifestazione con presenza di public, presented as part of a course on safety in sports facilities, Rome. 
[9] Vigne G., Marsella S., L'approccio ingegneristico alla sicurezza antincendio nel sistema normativo italiano, in Antincendio, EPC Rome, 2001.

[10] Bruno A., Norme di riferimento: aspetti che caratterizzano gli impianti sportive, presented as part of a course on safety in sports facilities, Rome.

[11] Bruno A., Corso, Rischi specifici, presented as part of a course on safety in sports facilities, Rome.

[12] Di Sivo M., La gestione della sicurezza degli impianti sportivi.
[13] Editrice il campo, Nuove tecnologie per la sicurezza negli stadi, http.//sportindustry.com, last consulted 31/01/2015.

[14] Antoniotti M., Guida ai piani di sicurezza.

[15] Di Nenno P. J. (ed.) The SFPE Handbook of Fire Protection Engineering, Second Edition, Society of Fire Protection Engineers, Bethesda, 1995.

[16] Marzotti L., Approccio ingegneristico alla sicurezza antincendio,

http://www.vigilfuoco.it/aspx/ReturnDocument.aspx?IdDocu mento $=47$, last consulted 31/01/2015. 